\title{
Estudo do Efeito do Envelhecimento sob Radiação UV no Transporte de Água em Filmes de PET Reciclados de Bebidas Carbonatadas
}

\author{
Raquel B. Vichessi, Adhemar C. Ruvolo Filho \\ Departamento de Química, UFSCar
}

\begin{abstract}
Resumo: Este trabalho descreve um estudo sobre o efeito do envelhecimento sob radiação UV no transporte de água em filmes planos de PET reciclados de garrafas de bebidas carbonatadas. A partir do formalismo termodinâmico utilizando a relação de Eyring e os resultados de coeficientes de permeabilidade, foram determinadas a entropia e a entalpia de ativação para o transporte da água. Estas funções representadas num gráfico de efeito de compensação termodinâmica permitiram correlacionar a degradação do material, avaliada via espectroscopia na região do infravermelho com transformada de Fourier, com o transporte de água. Foram analisados os possíveis efeitos da presença de estabilizantes, pigmentos e história de processamento.
\end{abstract}

Palavras-chave: PET, reciclagem, transporte de água, efeito de compensação termodinâmica, degradação, FT-IR.

\section{Study of the UV Ageing Effect on Water Transport through PET Films Recycled from Beverage Bottles}

\begin{abstract}
This work describes a study about the UV ageing effect on water transport through PET film sheets recycled from beverage bottles. Using a thermodynamic formalism based on the Eyring relationship and results of water permeability coefficient, it is possible to determine the entropy and enthalpy of activation for the water transport process. These functions were correlated using the compensation thermodynamic plot and correlations were made between the degradation of the PET samples, measured by FTIR, and transport properties. Also, possible effects from the presence of stabilizers, pigments and processing history were analyzed.
\end{abstract}

Keywords: PET, recycling, water transport, thermodynamic compensation effect, degradation, FTIR.

\section{Introdução}

Nas últimas décadas, a aplicação de termoplásticos cresceu aceleradamente devido às propriedades que estes materiais apresentam: tais como, boa moldabilidade a quente e resistência mecânica, baixa densidade, transparência, capacidade de coloração e/ou impressão, boa resistência mecânica e principalmente baixo custo ${ }^{[1,2]}$. O problema do descarte dos resíduos poliméricos, que ocupam grande parte do lixo urbano mundial e são de difícil decomposição, surgiu em conjunto com o consumo acelerado.

A reciclagem destes resíduos permitiria em parte, solucionar o problema ambiental bem como possibilitaria o desenvolvimento de novos materiais a partir de blendas e compósitos que agregam maior valor ao material pósconsumo. Devido à baixa reciclabilidade dos polímeros, o custo de recuperação pode ser superior ao da obtenção da matéria-prima, além da qualidade do material reciclado ser inferior à resina virgem ${ }^{[1]}$. Entretanto, tomando-se como exemplo materiais commodities, os custos de recuperação do poli(tereftalato de etileno)(PET) e polietileno de alta densidade (HDPE) são inferiores ao valor da matéria-prima, com o preço do barril de petróleo a U\$ 20,00 e U\$ 35,00. Em 2005, o valor do barril de petróleo situou-se na faixa de U\$ 50,00, tornando assim a reciclagem destes materiais economicamente viável ${ }^{[3]}$.

Existem três tipos de processos de reciclagem polimérica: mecânica, química e energética. A reciclagem mecânica utiliza o polímero pós-industrial (primária) ou pós-consumo (secundária); no processo químico ocorre a despolimerização ou degradação a produtos de baixo peso molecular e no energético é recuperada a energia de resíduos poliméricos por incineração controlada ${ }^{[2]}$. No Japão e na Alemanha, o processamento de sucata plástica pela sua inserção em altos-fornos siderúrgicos mostrou ser uma técnica economicamente viável na reciclagem energética. Outros países como os Estados Unidos também estão analisando esse pro-

Autor para correspondência: Adhemar C. Ruvolo Filho, Grupo de Processamento e Propriedades em Polímeros, Centro de Ciências Exatas e de Tecnologia, Departamento de Química, UFSCar, Caixa Postal 676, CEP: 13560-905, São Carlos, SP, Brasil. E-mail: adhemar@ufscar.br 
cesso com resultados satisfatórios ${ }^{[1]}$. No Brasil, predomina a reciclagem mecânica e em menor escala, a química.

Pesquisas realizadas sobre a composição do lixo urbano, nas grandes cidades brasileiras, mostraram que os principais polímeros encontrados nos resíduos sólidos são o polietileno de alta densidade e de baixa densidade (HDPE e LDPE), o PET, o poli(cloreto de vinila) (PVC) e o polipropileno (PP). Dados levantados até o ano de 1996, mostraram que o polietileno (34\%) foi o responsável pelo maior percentual na composição do lixo, seguido do PET (18\%) $)^{[4]}$. A partir de 2003, uma pesquisa realizada pelo Instituto Sócio-Ambiental do Plástico (Plastivida) ${ }^{[5]}$ destacou que cerca de $16,5 \%$ dos resíduos plásticos (pós-consumo) são reaproveitados através da reciclagem mecânica. Foi também observado que houve uma significativa mudança na composição do lixo urbano, no qual o PET assumiu a maior porcentagem $(39,3 \%)$ contra a queda de HDPE (16,6\%) encontrado nesses resíduos. Em menores quantidades foram encontrados outros polímeros como o PVC (16,5\%), HDPE/LDPE $(13,2 \%)$ e PP $(8,2 \%)$.

\section{Poli (tereftalato de etileno)}

O poli (tereftalato de etileno) - PET - é um poliéster amplamente utilizado, sendo que sua aplicação na produção de embalagens iniciou-se nos anos 90. A leveza e transparência, entre outras propriedades, impulsionaram a alta produção de resina PET, que em 2005 atingiu cerca de 7 milhões de toneladas anuais na demanda mundial ${ }^{[6]}$. $\mathrm{O}$ grande volume deste polímero nos aterros (19\%) deve-se ao baixo incentivo fiscal ${ }^{[7]}$. No Brasil, a reciclagem é sustentada pela catação informal em ruas e lixões. Atualmente, a reciclagem do PET atingiu uma cifra na ordem de 180.000 ton/ano, a qual está suprindo o déficit de resina PET no país.

O PET ganhou forte expressão no mercado de embalagens, sendo majoritariamente na fabricação de garrafas de refrigerantes ${ }^{[7]}$. Para manter níveis desejáveis de pressão, evitando a perda de gás carbônico e sabor, como também impedindo a introdução de oxigênio, a embalagem deve possuir boas propriedades de barreira. Entretanto, no PET, o coeficiente de permeação de gases é alto. A permeação dessas substâncias limita a vida de prateleira de uma garrafa PET padronizada (como capacidade de meio litro e tampa normal) surpreendentemente para cerca de 4 a 6 semanas $^{[8]}$. O PET reciclado possui ainda maiores coeficientes de permeação devido às degradações sofridas nos processos de recuperação mecânica e na presença de contaminantes.

A presença de contaminantes no PET pós-consumo impede que o material reciclado retorne na forma de embalagens alimentícias. Segundo Torres et al. ${ }^{[9]}$, resíduos de PVC ou mesmo a presença de água levam à clivagem de cadeia, um aumento nos grupos terminais carboxil, que reduz a massa molecular, a viscosidade intrínseca e resulta numa diminuição das propriedades mecânicas do material. Conseqüentemente, a cristalização do PET reciclado durante o processo de fusão é maior em relação à resina virgem, devido à degradação térmica. Assadi et al. ${ }^{[10]}$ em seus estudos, demonstrou as transformações estruturais irreversíveis ocorridas durante o processo de extrusão do PET, devido às reações de cadeia cruzada (degradação hidrolítica). O PET também pode sofrer degradação hidrolítica em temperaturas acima de $180{ }^{\circ} \mathrm{C}$, tendo como produto principal o acetaldeído ${ }^{[11,12]}$.

O PET reciclado é utilizado na fabricação de fibras, materiais não-tecidos, cordas, embalagens, cerdas, fitas de arquear e tubulações de esgoto predial ${ }^{[13]}$. Existem embalagens que utilizam o sistema de multicamadas que impedem o contato direto do PET reciclado com o alimento através de camadas de resina virgem. O tratamento com radiação gama também é utilizado para a esterilização do PET contaminado ${ }^{[14]}$.

Diversos estudos correlacionam a morfologia do PET com suas propriedades de barreira ${ }^{[15-17]}$. No caso de polímeros semicristalinos, o PET apresenta um decréscimo na permeabilidade gasosa com a cristalinidade. Esse efeito deve-se a dois fatores. Primeiro, a formação de cristais impermeáveis na estrutura diminui a região amorfa na qual as moléculas gasosas podem passar. Segundo, os cristais impermeáveis aumentam a tortuosidade do caminho percorrido por essas moléculas (impedância geométrica) ${ }^{[18]}$. Natu et al. ${ }^{[18]}$ observaram que em regiões não-cristalinas as propriedades de barreira, antes da colisão de esferulitos ocorrer, são governadas pelo tamanho e número de esferulitos. Ruvolo-Filho et al. ${ }^{[19]}$ demonstraram que em função da história de processamento pode ocorrer orientação bidimensional da região amorfa originando uma terceira fase denominada mesofase ou região amorfa rígida. Michaels et al. ${ }^{[17]}$ estudaram a difusão de gases através do PET pelas leis de Fick, concluindo que a difusividade é proporcional à fração de volume da região amorfa.

Orchard et al. ${ }^{[22]}$ estudaram os coeficientes de permeação e difusão para o oxigênio e o vapor de água, em filmes de PET com estiramento biaxial. Foi observado que a densidade e a orientação molecular influem nas propriedades de barreira do PET, sendo que a densidade da amostra é um fator muito importante no coeficiente de permeação do oxigênio, provavelmente devido à correlação entre esta propriedade e a fração em volume de material cristalino, que por sua vez está diretamente relacionada com a porcentagem de confôrmeros trans. A dependência da concentração de confôrmeros trans e gauche encontrada em filmes com orientação uniaxial, na qual o confôrmero trans é considerado a fração impermeável do material, não foi tão clara para filmes de PET orientados biaxialmente.

A exposição ao meio ambiente pode causar mudanças na estrutura química dos polímeros, levando a uma redução no tamanho molecular e à formação de grupos carbonilas e hidroxiperóxidos nas moléculas ${ }^{[23]}$. Essas degradações podem afetar as propriedades físicas e químicas nos polímeros. Foram observados como efeitos de degradações: o aumento na cristalinidade durante a fotodegradacão $0^{[24,25]}$, degradação térmica ${ }^{[26,27]}$ e irradiação de alta energia ${ }^{[28,29]}$; o descréscimo na cristalinidade principalmente durante a irradiação gama $^{[30,31]}$, uma modificação na morfologia, como destruição de esferulitos ${ }^{[32]} \mathrm{e}$ alteração na rede cristalina ${ }^{[33,34]}$. 
Fechine et al. ${ }^{[23]}$ investigaram as mudanças estruturais ocorridas durante a fotodegradação do PET. Eles observaram que amostras expostas à radiação, abaixo da temperatura de transição vítrea, não apresentaram um aumento na cristalinidade durante a exposição.

No PET, o principal grupo cromóforo apresenta absorção de radiação UV na faixa de $240-320 \mathrm{~nm}$ :

$$
-\mathrm{O}-\mathrm{CO}-\mathrm{C}_{6} \mathrm{H}_{4}-\mathrm{CO}-\mathrm{O}-
$$

ocorrendo uma forte absorção próximo de $310 \mathrm{~nm}^{[35]}$.

No processo de degradação do PET concorrem entre si duas reações: a fotólise e a foto-oxidação. Essas reações envolvem cisão de cadeia, resultando na formação de produtos gasosos como $\mathrm{CO}, \mathrm{CO} 2$ e grupos terminais carboxílicos ${ }^{[36]}$. O grau de degradação atingido dependerá da intensidade que o filme é exposto à luz ultravioleta. Irradiações de alta energia geram transformações no seio da estrutura, enquanto que em menores intensidades a deterioração ocorre somente na superfície.

Segundo Ilišković et al. ${ }^{[35]}$ não há relação linear entre o tempo de irradiação e as mudanças ocorridas nas propriedades do PET exposto à luz UV. Propriedades como tração, alongamento e viscosidades específica diminuem enquanto que a quantidade de grupos terminais carboxílicos aumenta. Este fenômeno pode ser explicado pela formação de uma fina camada foto-oxidada do polímero, na superfície, que age como uma barreira à absorção de luz, assim a fotodegradação do PET ocorre essencialmente na superfície da amostra.

A Figura 1 mostra o mecanismo para a reação de degradação do PET sugerido por Rabello et al. ${ }^{[37]}$. Neste esquema, os radicais $R$ podem ser gerados por reações tipo Norrish ${ }^{[38]}$ ou nesta reação cíclica.

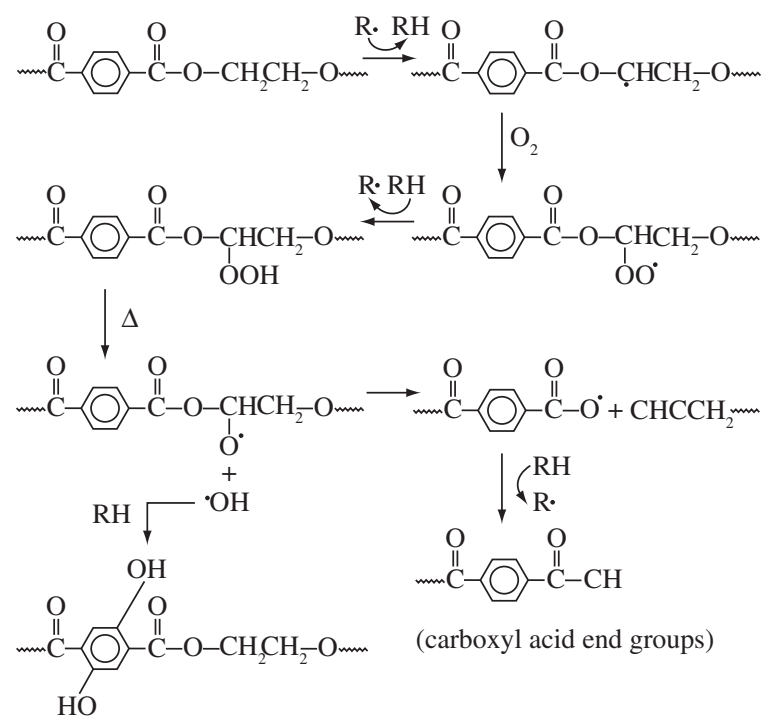

(mono or dihydroxy terephthalate)

Figura 1. Reações foto-oxidativas do PET durante exposição UV para grupos terminais carboxila ${ }^{[37,38]}$.
Este trabalho tem como objetivo um estudo sobre o efeito do envelhecimento sob radiação UV no transporte de água em filmes planos de PET reciclados de garrafas de bebidas carbonatadas. A partir do formalismo termodinâmico utilizando a relação de Eyring e os resultados de coeficientes de permeabilidade, será determinada a entropia e a entalpia de ativação para o transporte da água. Estas funções representadas num gráfico de efeito de compensação termodinâmica serão correlacionadas com a degradação do material, avaliada via espectroscopia na região do infravermelho com transformada de Fourier, com o transporte de água. Também serão analisados os possíveis efeitos da presença de estabilizantes, pigmentos e história de processamento.

\section{Experimental}

\section{Material de estudo}

Os materiais estudados neste trabalho serão designados por BV (branco virgem, peletes de resina RHOPET $^{\circledR}$ S80), BR (branco reciclado, proveniente de flakes de garrafas carbonatadas incolores), GB (garrafa branca, embalagem incolor pós-consumo), VV (verde virgem, peletes provenientes de flakes de garrafa carbonatada verde com adição de estabilizantes), VR (verde reciclado, proveniente de flakes de garrafas carbonatadas verdes) e GV (garrafa verde, embalagem verde pós-consumo). Esses materiais foram obtidos por doação de suas respectivas indústrias de origem, sendo BV e VV doados pela Rhodia Ster, atual M\&G. Os flakes de VR e BR foram doados pela indústria recicladora Embrapol.

Os materiais BR, VR, GB e GV apresentam grande quantidade de impurezas. Para a limpeza de BR e VR, pesou-se $600 \mathrm{~g}$ do material e colocou-os em um recipiente contendo $2 \mathrm{~L}$ de água e sabão em pó e a lavagem foi realizada com o auxilio de um agitador mecânico por 24 horas. Em seguida, foram efetuadas as etapas de enxágüe, flotação, catação e filtragem. Foi realizado um segundo enxágüe sobre uma peneira para a eliminação de resíduos sólidos. O material foi seco em ambiente aberto e em seguida, em estufa a $75{ }^{\circ} \mathrm{C}$ por 24 horas. As amostras GB e $\mathrm{GV}$ foram lavadas com detergente líquido e água e secas em ambiente aberto.

\section{Obtenção de filmes}

Para o processamento de filmes finos por termoprensagem de BV, BR, VV e VR, os materiais foram previamente secos a $140{ }^{\circ} \mathrm{C}$ em estufa por 6 horas. Os grânulos foram colocados entre placas de poliimidas e estas entre placas de latão, previamente envolvidas como o desmoldante Goracoat CGV 3302C - Goldshmidt Indústrias Químicas Ltda (aditivo Poliuretana). No processo foi utilizada uma termoprensa Carver, nas seguintes condições de processamento: 
- $\mathrm{T}_{\mathrm{p}}=270 \pm 5^{\circ} \mathrm{C}$;

- $\mathrm{t}_{\mathrm{f}}=2,5$ minutos;

- $\mathrm{t}_{\mathrm{p}}=30$ segundos; $\mathrm{e}$

- $\mathrm{P}_{\mathrm{n}}^{\mathrm{p}}=12$ kgf.cm ${ }^{-2}$.

onde $\mathrm{T}_{\mathrm{p}}$ é a temperatura de fusão para o processamento, $\mathrm{t}_{\mathrm{f}}, \mathrm{o}$ tempo de fusão, $t_{\mathrm{p}}$, o tempo em que foi aplicada pressão sobre o material e $\mathrm{P}_{\mathrm{n}}$, a pressão nominal utilizada.

Após aplicada a pressão, o conjunto foi resfriado rapidamente em banho de gelo. Todas as amostras obtidas dos materiais estudados foram cortadas com o auxilio de uma cunha e suas espessuras, medidas em um micrômetro, MITOTOYO (10-25). As espessuras das amostras obtidas por termoprensagem e a partir de garrafas pós-consumo estão na faixa de 80-300 $\mu \mathrm{m}$.

\section{Envelhecimento de amostras de PET}

Um conjunto de amostras, previamente cortadas e com suas espessuras medidas, foi envelhecido em diferentes intervalos de tempo: 60, 120, 180, 240 e 300 horas, em câmara de radiação UV dotada de lâmpada de vapor de mercúrio da marca Germitec modelo G110T5172L ultrapura, que emite luz UV no comprimento de onda na ordem de $290 \mathrm{~nm}$, com 16 watts de potência. Os ensaios foram conduzidos a temperatura de $25^{\circ} \mathrm{C}$ e no interior da câmara, as amostras foram dispostas a uma distância de $14,5 \mathrm{~cm}$ da fonte de radiação UV.

\section{Transporte de água}

Os ensaios de transporte de água foram realizados de acordo com a norma ASTM E96-80, em duplicatas para cada material analisado. Para a realização destes ensaios, as amostras foram colocadas em copos de Payne contendo água e fixadas por dois anéis de borracha e um metálico, como mostra a Figura 2. Os sistemas montados foram colocados em dessecadores contendo pentóxido de fósforo $\left(\mathrm{P}_{2} \mathrm{O}_{5}\right)$. Os ensaios foram realizados em banhos de água termostatizados nas temperaturas de 15,25 e $35^{\circ} \mathrm{C}$.

Dado que a história de processamento, no caso das amostras retiradas diretamente das garrafas com espessura da ordem de $300 \mu \mathrm{m}$, foi preservado, então para efeito de comparação com as amostras que foram termoformadas, os resultados de permeabilidade foram todos normalizados para a espessura de $80 \mu \mathrm{m}$.

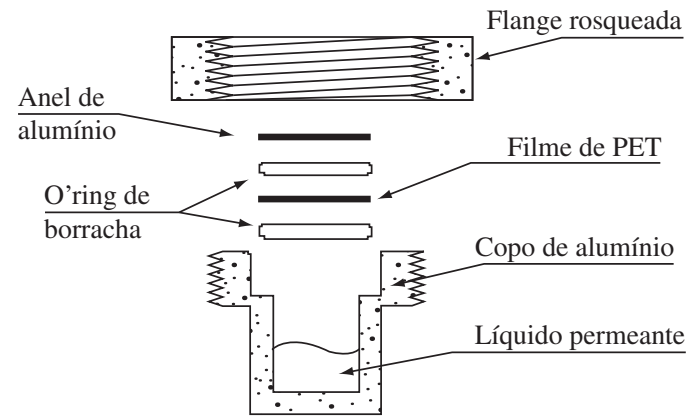

Figura 2. Sistema Copo de Payne utilizado nos experimentos de permeação de água.

\section{Caracterização por espectroscopia de infravermelho}

Os corpos de prova envelhecidos sob radiação UV, foram caracterizados por espectroscopia de infravermelho com transformada de Fourier (FT-IR) para a análise da formação de grupos terminais carboxílicos. O equipamento utilizado foi Nicolet Protégé ${ }^{\mathrm{TM}} 460$ ESP, sendo a faixa de número de onda utilizada de $4000-400 \mathrm{~cm}^{-1}$ e o índice de carboxila foi determinado, após 256 varreduras com resolução de $4 \mathrm{~cm}^{-1}$, através da relação:

$$
i_{\text {carboxila }}=\frac{\text { absorção em } 3290 \mathrm{~cm}^{-1}}{\text { absorção em } 2970 \mathrm{~cm}^{-1}}
$$

\section{Resultados e Discussão}

Para um processo físico e/ou químico ocorrer, a energia necessária para sua ativação deve ser maior ou igual à barreira energética que separa os estados inicial e final do fenômeno. Assim, a quantidade de energia envolvida nesta transformação é representada pela entalpia de ativação. Outra função de estado, a entropia de ativação, caracteriza a tendência do processo ao equilíbrio. A correlação entre entalpia e entropia de ativação é demonstrada conforme o formalismo termodinâmico de Eyring ${ }^{[39]}$, expresso na Equação 2:

$$
\mathrm{t}=(\mathrm{h} / \mathrm{k} \cdot \mathrm{T}) \exp \left(-\Delta \mathrm{S}^{\neq} / \mathrm{R}\right) \exp \left(\Delta \mathrm{H}^{\neq} / \mathrm{RT}\right)
$$

sendo $\mathrm{h}=$ constante de Boltzmann, $\mathrm{k}=$ constante de Plank, $\mathrm{T}=$ temperatura do sistema, $\Delta \mathrm{H}^{\neq} \mathrm{e} \Delta \mathrm{S}^{\neq}$, as entalpia e entropia de ativação do processo de difusão.

$\mathrm{O}$ processo físico da difusão de um líquido num dado material, pode ser analisado em termos energéticos. Considerando os valores de permeabilidade em unidades de área/ tempo $\left(\mathrm{cm}^{2} \cdot \mathrm{s}^{-1}\right)$ e o tempo (t) em segundos, necessário para ocorrer o processo de difusão em um material, podemos aplicar o formalismo citado acima para este processo. Sendo a permeabilidade $\left(\mathrm{P}_{\mathrm{w}}\right)$ inversamente proporcional ao tempo $(\mathrm{t})$ e proporcional à constante de velocidade $\left(\mathrm{k}_{\mathrm{v}}\right)$, isto é, $\mathrm{t} \alpha 1 / \mathrm{k}_{\mathrm{v}}$, então $P_{w} \alpha k_{v}$, obtemos uma nova forma da Equação 2:

$$
\mathrm{P}_{\mathrm{w}}=(\mathrm{A} \cdot \mathrm{k} \cdot \mathrm{T} / \mathrm{h}) \exp \left(\Delta \mathrm{S}^{\neq} / \mathrm{R}\right) \exp \left(-\Delta \mathrm{H}^{\ddagger} / \mathrm{RT}\right)
$$

onde $\mathrm{A}$ é a área geométrica da amostra, exposta à difusão.

A Equação 3 na forma logarítimica fica:

$$
\ln \left(\mathrm{P}_{\mathrm{w}} / \mathrm{A} . \mathrm{T}\right)=\ln \mathrm{k} / \mathrm{h}+\Delta \mathrm{S}^{\neq} / \mathrm{R}-\Delta \mathrm{H}^{\neq} / \mathrm{RT}
$$

e portanto a representação de $\ln (\mathrm{Pw} / \mathrm{A} . \mathrm{T})$ em função de 1/T é linear, como está mostrado um resultado típico na Figura 3, sendo o coeficiente angular igual a $\Delta \mathrm{H}^{\neq} / \mathrm{R}$, e o coeficiente linear igual a ln $\mathrm{k} / \mathrm{h}+\Delta \mathrm{S}^{\neq} / \mathrm{R}$ o que permite a determinação de $\Delta \mathrm{H}^{\neq}$e $\Delta \mathrm{S}^{\neq}$. Os valores da entalpia e da entropia de ativação podem então ser relacionados linearmente em um gráfico denominado Efeito de Compensação Termodinâmico. Sua importância reside na possibilidade de avaliar diretamente o peso relativo das duas funções termodinâmicas que compõem a função de Gibbs, ou seja $\Delta \mathrm{G}^{\neq}=\Delta \mathrm{H}^{\neq}-\mathrm{T} \Delta \mathrm{S}^{\neq}$. 
Como a entalpia e a entropia de ativação correspondem às energias envolvidas entre os estados inicial e ativado do processo, quanto menor a quantidade entálpica, mais rapidamente ocorrerá a transformação. Os valores negativos de entropia de ativação indicam maior proximidade ao estado de equilíbrio do processo difusional, isto é, maior espontaneidade ao estado final.

A Figura 4 mostra o efeito de compensação termodinâmica para o grupo de amostras incolores e na Figura 5 são mostrados os coeficientes de permeabilidade da água, obtidos a $25^{\circ} \mathrm{C}$, em função do tempo de envelhecimento.

Analisando a Figura 5, nota-se uma diminuição contínua da permeabilidade para as amostras BR, no intervalo de 0 a 300 horas sob radiação UV, corroborando com uma acentuada redução na variação da compensação entrópica, da ordem de $-0,14 \mathrm{~kJ} \mathrm{~mol}^{-1}\left(\Delta \mathrm{S}_{\text {amostra envelhecida }}-\Delta \mathrm{S}^{\neq}{ }_{\text {amostra original }}\right)$. Para as amostras BV ocorre um declínio em $\mathrm{P}_{\mathrm{w}}$ até 120 horas, retornando a crescer entre 120 e 180 horas, seguido de uma diminuição entre 180 e 300 horas; os valores de variação da compensação entrópica são menores para este material em

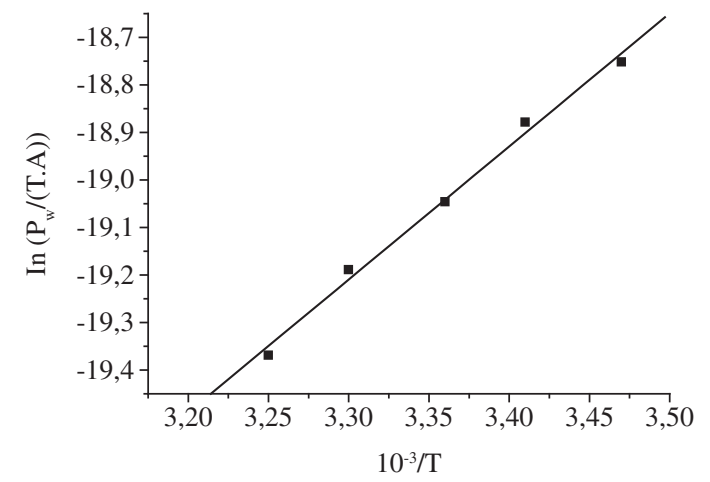

Figura 3. Representação gráfica do formalismo de Eyring.

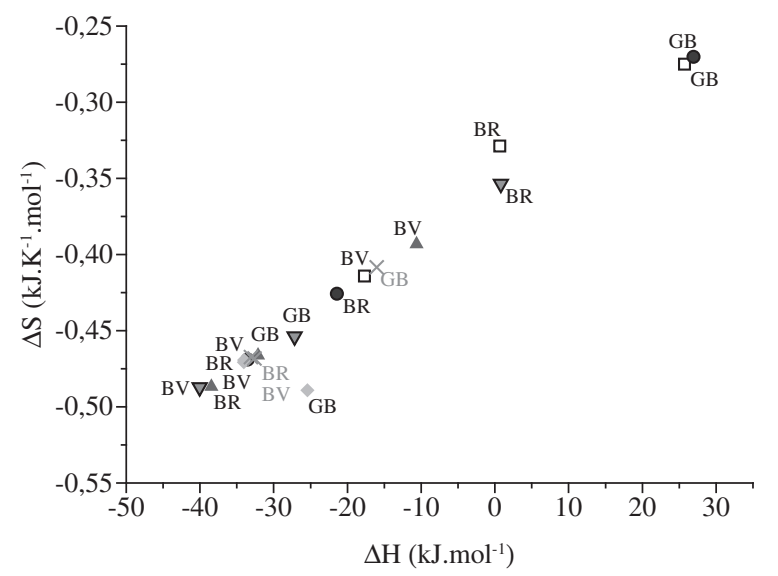

$\square$ Originais

- Envelhecidas sob radiação por 60 horas de UV

- Envelhecidas sob radiação por 120 horas de UV

$\nabla$ Envelhecidas sob radiação por 180 horas de UV

- Envelhecidas sob radiação por 240 horas de UV

$\times$ Envelhecidas sob radiação por 300 horas de UV

Figura 4. Efeito de compensação termodinâmica para as amostras incolores. relação a BR, apresentando-se na faixa de $-0,054 \mathrm{~kJ} \cdot \mathrm{mol}^{-1}$. Entretanto, observa-se uma aumento em $\mathrm{P}_{\mathrm{w}}$ após 300 horas de envelhecimento nas amostras GB e um diminuição na variação da compensação entrópica da ordem de $-0,133$ kJ.mol ${ }^{-1}$. Este fato contradiz a suposição de que a diminuição de $\Delta \mathrm{S}^{\neq}$ está sempre relacionada a uma queda na permeabilidade, como nos casos anteriores.

O grupo de amostras com pigmento verde é representado nas Figuras 6 e 7, onde os resultados de $\mathrm{P}_{\mathrm{w}}$ também foram obtidos na temperatura de $25^{\circ} \mathrm{C}$.

A partir de 120 horas, ocorre um brusco aumento na permeabilidade para as amostras VR, seguido de uma diminuição desta propriedade até o final de 300 horas de envelhecimento (Figura 6). A variação da compensação entrópica para VR é pequena após 300 horas sob radiação UV, situando-se na faixa de $-0,006 \mathrm{~kJ} \cdot \mathrm{mol}^{-1}$. Por outro lado, o acentuado aumento na permeabilidade e na variação da compensação entrópica $\left(-0,027 \mathrm{~kJ} \cdot \mathrm{mol}^{-1}\right)$, após 300 horas de envelhecimento, são observados para as amostras VV. Novamente, um comportamento atípico é observado para as amostras retiradas diretamente de garrafas pós-consumo. Em GV, há um aumento na variação da entropia após 300 horas sob radiação UV, indicando uma maior facilidade em relação ao processo físico de transporte de água, porém observando a Figura 7, nota-se uma acentuada diminuição na permeabilidade após o mesmo período.

Como explicar os comportamentos diferenciais dentro de seus grupos para GB e GV, como também a contradição observada em VV? A partir da Tabela 1, na qual são apresentados os valores de índices de grupos terminais carboxila $\left(\mathrm{i}_{\text {carboxila }}\right)$ determinados por FT-IR, obtidos para as diferentes amostras, em função do tempo de envelhecimento sob radiação UV, tentar-se-á correlacionar o comportamento da permeabilidade e possíveis reações de degradação nos diversos materiais estudados neste trabalho.
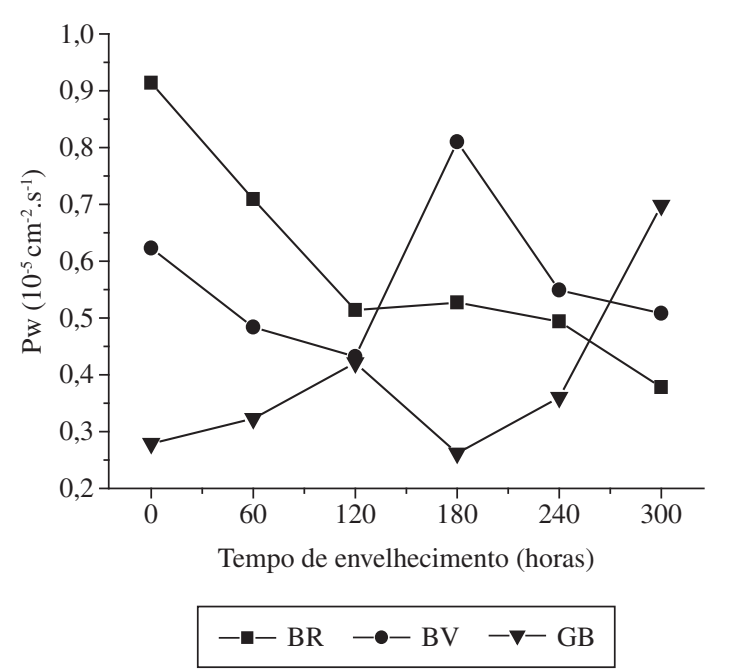

Figura 5. Permeabilidade normalizada da água (Pw) em função do tempo de exposição UV, para amostras pigmentadas verdes. 


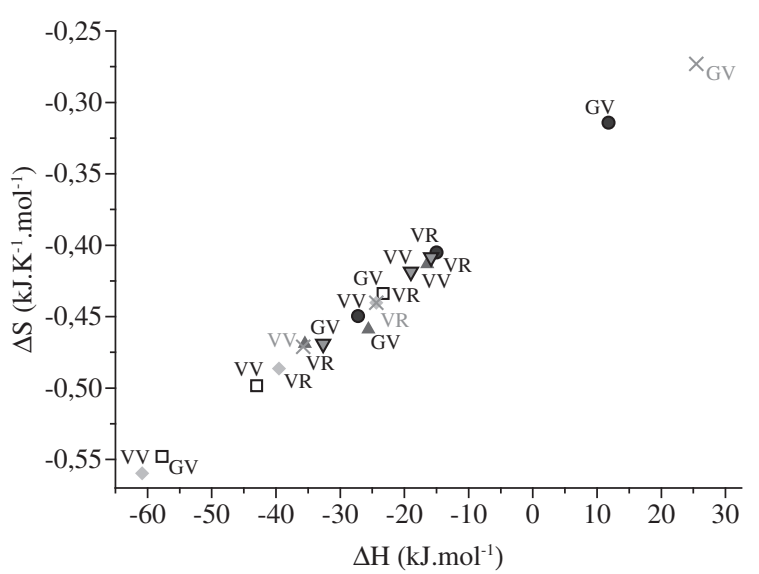

$\square$ Originais

- Envelhecidas sob radiação por 60 horas de UV

- Envelhecidas sob radiação por 120 horas de UV

$\nabla$ Envelhecidas sob radiação por 180 horas de UV

- Envelhecidas sob radiação por 240 horas de UV

$\times$ Envelhecidas sob radiação por 300 horas de UV

Figura 6. Efeito de compensação termodinâmica para as amostras com pigmento verde.

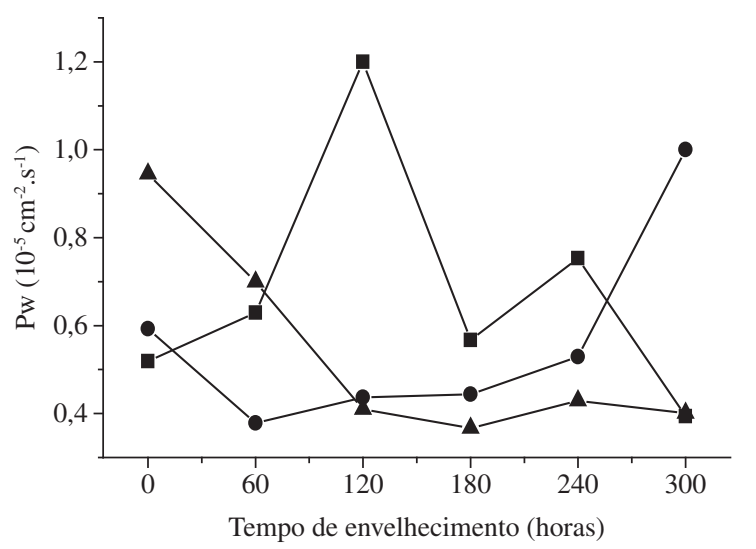

$\longrightarrow-V R \rightarrow V V \rightarrow-G V$

Figura 7. Permeabilidade normalizada da água $(\mathrm{Pw})$ em função do tempo de exposição UV, para amostras pigmentadas verdes.

Tabela 1. Valores de índices de grupos terminais carboxila $\left(\mathrm{i}_{\text {carboxila }}\right)$ determinados por FT-IR, obtidos para as diferentes amostras em função do tempo de envelhecimento sob radiação UV.

\begin{tabular}{ccccccc}
\hline $\begin{array}{c}\text { Amostras/ } \\
\text { envelhe- } \\
\text { cimento } \\
\text { (horas) }\end{array}$ & $\mathbf{0}$ & $\mathbf{6 0}$ & $\mathbf{1 2 0}$ & $\mathbf{1 8 0}$ & $\mathbf{2 4 0}$ & $\mathbf{3 0 0}$ \\
\hline BR & 0,11 & 0,12 & 0,13 & 0,09 & 0,12 & 0,18 \\
VR & 0,11 & 0,15 & 0,11 & 0,09 & 0,11 & 0,25 \\
BV & 0,11 & 0,131 & 0,09 & 0,05 & 0,09 & 0,09 \\
VV & 0,10 & 0,13 & 0,10 & 0,08 & 0,10 & 0,09 \\
GB & 0,09 & 0,17 & 0,14 & 0,00 & 0,08 & 0,29 \\
GV & 0,08 & 0,01 & 0,02 & 0,11 & 0,06 & 0,17 \\
\hline
\end{tabular}

Analisando BR e VR, verifica-se um aumento acentuado nos grupos carboxílicos após 300 horas de envelhecimento, correspondendo a uma diminuição em $\mathrm{P}_{\mathrm{w}}$. Uma possível explicação para este fenômeno seria devido à interação dos grupos carboxílicos polares com a água.

Os ensaios realizados com os materiais virgens demonstram maior resistência ao transporte de água, após a irradiação. As diferentes amostras estudadas, neste trabalho, possuem estabilizantes UV, porém somente BV não contém um envelhecimento natural ocorrido pela vida de prateleira do PET. O material verde virgem (VV) é considerado de segunda geração, pois provém da reciclagem e sofre uma maior aditivação de estabilizantes UV neste último ciclo. Esses aditivos proporcionam menores quantidades de grupos terminais carboxila. A permeabilidade nestes materiais diminui até que irradiação anule o efeito do estabilizante, o crescimento acentuado da permeação ocorre a partir de 240 horas para VV. Segundo a literatura ${ }^{[40]}$, a presença do pigmento num material polimérico pode induzir a um marcante efeito de proteção contra a radiação UV, ou então interagir com esta radiação, catalisando ou acelerando a degradação do polímero. Alternativamente, o pigmento pode interagir com os estabilizantes presentes no material, ou ainda reduzir a ação destes aditivos, um efeito pouco entendido ${ }^{[40]}$.

Para as amostras GB, observa-se um aumento dos grupos carboxílicos e um acentuado acréscimo na permeabilidade. Neste caso, ocorrendo interação destes grupos carboxílicos terminais com a água, formar-se-iam clusters de água. Tendo em conta que a morfologia da amostra GB processada via sopro é prevalentemente constituída por uma estrutura fibrilar, os clusters poderiam localizar-se uns próximos aos outros e, portanto, estatisticamente aumentar-se-ia a probabilidade de seu agrupamento ou interconexão na forma de canalículos, o que facilitaria o processo de permeação da água. Surpreendentemente, no caso das amostras $\mathrm{GV}$, cujo processo também é via sopro, observa-se um aumento acentuado de grupos carboxílicos após 300 horas de envelhecimento, entretanto a permeabilidade diminui. Considerando que a única diferença entre essas amostras é a presença do pigmento verde, poderse-ia apresentar na forma de hipóteses, para uma futura comprovação, duas explicações: i) a interação entre o pigmento e a água, reduzindo a permeabilidade; e ii) a reação de transesterificação catalisada pela presença do pigmento verde que aumentaria o livre caminho médio para a permeação de água.

Analisando as amostras antes do envelhecimento, observa-se nas Figuras 5 e 7 que entre as amostras termoprensadas, BR tem maior permeabilidade que VR, enquanto que nas obtidas via sopro, $\mathrm{GV}$ tem maior $\mathrm{P}_{\mathrm{w}}$ que GB. No entanto, uma análise detalhada dessas diferenças torna-se, no caso das amostras GB e GV, praticamente impossível por tratar-se de materiais reciclados que não se tem controle sobre o ciclo de vida.

Para as amostras BR e VR, provenientes do reprocessamento respectivo de $\mathrm{GB}$ e $\mathrm{GV}$, o processo de fusão, termoprensagem e resfriamento elimina as diferenças relacionadas 
à história inicial destes materiais. Entretanto, se ocorreu algum processo de degradação seguido de variação na distribuição da massa molar isto terá um efeito importante na cristalização do material. É conhecido que materiais que apresentam uma distribuição de massa molar de cadeias pequenas têm maior habilidade à cristalização que materiais que apresentam distribuição de massa molar referentes a cadeias mais longas. A partir dos resultados observados nas Figuras 5 e 7, o menor valor de permeabilidade encontrado para as amostras VR, sugere que este material provém de uma garrafa pósconsumo pigmentada mais degradada, ou que ele apresenta uma distribuição maior de massa molar com cadeias pequenas. A maior cristalinidade obtida nestas amostras explicaria um menor valor de permeabilidade.

Se lembrarmos que a primeira hipótese apresentada para as amostras GV após 300 horas de envelhecimento sob radiação UV foi a provável participação (como catalisador) do pigmento verde numa possível reação de transesterificação do PET, este fato, de certa forma, corrobora com a justificativa apresentada para a permeabilidade encontrada na amostra original VR. O que se pretende justificar é que o pigmento verde pode ter um papel determinante tanto na recombinação de segmentos da cadeia do PET via reações de transesterificação como no aceleramento das reações de degradação via cisão de cadeia, isto é, o pigmento pode interagir com a matriz, como também com a radiação. Estas hipóteses estão fundamentadas no fato de que o oxigênio e a água quando presentes no sistema polimérico contendo corantes ou pigmentos podem formar espécies iniciadoras dos processos fotodegradativos, através da participação direta dos corantes ou pigmentos como cromóforos ${ }^{[41]}$. É importante ainda assinalar que embora não temos a estrutura do pigmento verde utilizado na matriz comercial do PET, utilizado neste trabalho, é sabido que os principais pigmentos para uso neste tipo de poliéster pertencem aos grupos das ftalocianinas ou 2-amino antraquinona de cor verde.

\section{Conclusões}

Através de correlações entre funções termodinâmicas de estado, propriedades de transporte e índice de carboxila, foi possível avaliar de forma comparativa a influência da degradação em amostras de PET recicladas. A presença do pigmento nas amostras retiradas diretamente das garrafas verdes mostrou um efeito positivo mesmo após 300 horas de envelhecimento sob radiação UV. Com base nos resultados obtidos foi sugerida a hipótese de que o pigmento verde pode ter um papel importante nas reações de degradação, transesterificação e no processo de cristalização do PET reprocessado via termoformagem. Neste sentido parece ser de fundamental importância estudos mais detalhados sobre possíveis interações do pigmento: i) com a matriz polimérica na presença de radiação UV; ii) com a água; iii) com a matriz polimérica durante o processamento; e iv) com a radiação UV.

\section{Referências Bibliográficas}

1. Gorni, A. A. - Plast. Ind., 89, p.84 (2006).

2. Silva Spinacé, M. A. \& De Paoli, M. A. - Quim. Nova, 28, p.65 (2005).

3. Marconcini, J. M. - "Estudo da blenda poli (tereftalato de etileno) reciclado e poliolefinas recicladas.", Tese de Doutorado, Universidade Federal de São Carlos, Brasil (2005).

4. Agnelli, J. A. M. - Polímeros - Cienc Tecnol, 4, p.9 (1996)

5. http://www.plastivida.org.br/publicacoes_e_videos/plastivida_jornal.aspx. Acesso em 14 de abril de 2006.

6. http://www.cempre.org.br/fichas_tecnicas_pet.php. Acesso em 26 de fevereiro de 2005

7. http://www.jorplast.com.br/jpfev05/pag08.html. Acesso em 25 de fevereiro de 2005.

8. Schmachtenberg, E.; Hegenbart, A. \& Göbel, S. - Plast. Ind., 89, p.64 (2006).

9. Torres, N.; Robin, J. J. \& Boutevin, B. - Euro. Polym. J, 36, p.2075 (2000).

10. Assadi, R.; Colin, X. \& Verdu, J. - Polymer, 45, p.4403 (2004).

11. Ruvolo-Filho, A. \& Carvalho, G. M. - J. Macromol. Sci. - Phys., B 38, (3), p.305 (1999).

12. Villain, F.; Coudane, J. \& Vert, M. - Polym. Degrad. Stab., 43, p.431 (1994).

13. http://www.plastico.com.br/revista/pm342/reciclagem1. htm. Acesso em 28 de fevereiro de 2005.

14. Riganakos, K. A.; Koller, W. D.; Ethlermann, D. A. E.; Bauer, B. \& Kontominas, M. G. - Radiat. Phys. Chem. 54, p.527 (1999).

15. Vieth, W. R. - "Diffusion in and through polymers: Principles and Applications", Hanser, Munich (1991).

16. Hedenguist, M. \& Gedde, U. W. - Prog. Polym. Sci., 21, p.299 (1996).

17. Micheals, A. S.; Vieth, W. R. \& Barrie, J. - J. Appl. Phys., 34, p.13 (1963).

18. Natu, A. A.; Lofgren, E. A. \& Jabarin, S. A. - Polym. Eng. Sci., v.45, p.400 (2005).

19. Ruvolo-Filho, A. \& Carvalho, G. M. - J. Macromol. Sci. - Phys., B 35, (2), p.255 (1996).

20. Lin, J.; Shenogin, S. \& Nazarenko, S. - Polymer, 43, p.4733 (2002).

21. Lasoski, S. W. \& Cobbs, W. H. - J. Polym. Sci., 36, p.21 (1959).

22. Orchard, G. A. J.; Spiby, P. \& Ward, I. M. - J. Polym. Sci., 28, p.603 (1990).

23. Fechine, G. J. M.; Souto-Maior, R. M. \& Rabello, M. S. - J. Mat. Sci., 37, p. 4979 (2002). 
24. Chatterjee, N.; Basu, S.; Pelit, S. K. \& Maiti, M. M. - J. Polym. Sci., Polym. Phys. Edn. 33, p.1705 (1995).

25. Allen, N. S.; Edge, M.; Corrales, T.; Shah, M.; Holdswort, D.; Catalina F.; Peinado, C. \& Collar, E. P. Polymer, 37, p.2323 (1996).

26. Busfield, W. K. \& O’Donnel, J. H. - Euro. Polym. J., 15, p.197 (1979).

27. Zhao, Y.; Luo, Y. \& Jiang, B. - J. Appl. Polym. Sci., 50, p.1797 (1993).

28. Rabello, M. S. \& White, J. R. - Polymer, 38, p.6379 (1997).

29. Khabbaz, F.; Albertsson, A. C. \& Karlsson, S. - Polym. Degrad. Stab., 63, p.127 (1999).

30. Kostoski, D. \& Stojanovic, Z. - Polym. Degrad. Stab., 47, p.353 (1995).

31. Shinde, A. \& Salovey, R. - J. Polym. Sci., Polym. Phys. Edn., 23, p.1681 (1985).

32. Terselius, B.; Gedde, U. W. \& Jansson, J. F. - Polym. Eng. Sci., 22, p.422 (1982).

33. Ungar, G. \& Keller, A. - Polymer, 21, p.1273 (1980).
34. Kostoski, D.; Stojanovic, Z.; Gal, O. \& Stannett, V. - Radiat. Phys. Chem., 32, p.667 (1988).

35. Ilišković, N. \& Bravar, M. - Polym. Degrad. Stab., 15, p.173 (1986).

36. Blais, P.; Day, M. \& Wiles, D. M. - J. Appl. Polym. Sci., 17, p.1895 (1973).

37. Fechine, G. J. M.; Rabello, M. S.; Souto-Maior, R. M. \& Catalani, L. H. - Polymer, 45, p.2303 (2004).

38. Day, M. \& Wiles, D. M. - J. Appl. Polym. Sci., 16, p.203 (1972).

39. Crine, J. P. - J. Macromol. Sci., B 23, p.201 (1984).

40. Allen, N. S. \& Edge, M. - "Fundamentals of Polymer Degradation and Stabilisation", Elsevier Science Publishers Ltd, Netherlands (1992).

41. Saron, C. \& Felisberti, M. I. - Química Nova, 29, (1), p.124 (2006).

Enviado: $12 / 04 / 07$

Reenviado: 06/05/08

Aceito: $12 / 06 / 08$ 